\title{
Hyperviscosity Syndrome in Paraprotein Secreting Conditions Including Waldenstrom Macroglobulinemia
}

\author{
Allison Weaver, Samuel Rubinstein and Robert F. Cornell* \\ Division of Hematology and Oncology, Department of Internal Medicine, Vanderbilt University Medical Center, Nashville, TN, \\ United States
}

Hyperviscosity syndrome is a serious complication associated with high levels of paraproteins in patients with hematological malignancies. Therapeutic advances in disease control may reduce the incidence of hyperviscosity syndrome; however, management of acute cases requires an understanding of key symptoms and prompt treatment to mitigate serious consequences.

Keywords: hyperviscosity, plasma exchange, Waldenstrom, lymphoma, chemotherapy

OPEN ACCESS

Edited by:

Adam Finn Binder,

Thomas Jefferson University,

United States

Reviewed by:

Saad Zafar Usmani,

Levine Cancer Institute, United States

Michele Merli,

University of Insubria, Italy

*Correspondence:

Robert F. Cornell

robert.f.cornel/@vumc.org

Specialty section:

This article was submitted to

Hematologic Malignancies,

a section of the journal

Frontiers in Oncology

Received: 04 February 2020

Accepted: 27 April 2020

Published: 19 May 2020

Citation:

Weaver A, Rubinstein S and Cornell RF (2020) Hyperviscosity Syndrome in Paraprotein Secreting Conditions Including Waldenstrom Macroglobulinemia.

Front. Oncol. 10:815. doi: 10.3389/fonc.2020.00815

\section{INTRODUCTION}

Hyperviscosity syndrome (HVS) occurs in patients with hematological malignancies that secrete high levels of paraprotein (i.e, IgM, IgG, and IgA). It is most commonly observed in Waldenstrom macroglobulinemia (WM), affecting $10-30 \%$ of patients, and has been reported in $2-6 \%$ of patients with multiple myeloma (1-6). HVS has also been recently reported in a patient with

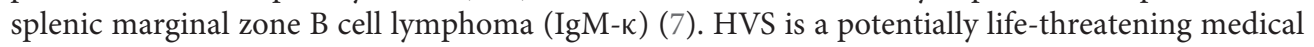
emergency that requires prompt recognition and intervention.

\section{PARAPROTEIN LEVELS AND HYPERVISCOSITY SYNDROME}

Viscosity can be measured in absolute terms in centipoise (cP), or in relative terms compared to the viscosity of water $(0.894 \mathrm{cP})$. A typical serum viscosity for a healthy patient is $1.5 \mathrm{cP}$, or 1.7 relative to water. The increased viscosity of serum relative to water relates primarily to its protein content. In contrast to most serum proteins, which are spherical in shape, immunoglobulins are relatively large but also linear in shape; thus, when they travel through the serum, they spin around their longitudinal axis, increasing serum viscous drag, and therefore viscosity. Serum viscosity is correlated with immunoglobulin levels for patients both with and without monoclonal gammopathies (8), but the concentration of immunoglobulins required to significantly increase viscosity depends on the specific type of paraprotein. IgM is pentameric and very large in size $(970 \mathrm{kDA})$, and serum viscosity can increase significantly with IgM levels as low as $3 \mathrm{~g} / \mathrm{dL}$, and IgM levels of $6 \mathrm{~g} / \mathrm{dL}$ or higher are associated with rapid development of hyperviscosity, with a median time to symptomatic HVS of 3 months $(9,10)$. IgA is smaller $(320 \mathrm{kDA})$ than IgM but circulates as a dimer and is associated with increased viscosity at levels of $6 \mathrm{~g} / \mathrm{dL}$ or greater $(5,11)$. IgG is relatively small $(180 \mathrm{kDA})$ and can require levels as high as $10 \mathrm{~g} / \mathrm{dL}$ to produce significant changes in viscosity, except for the IgG3 subtype, which has a tendency to aggregate and can increase viscosity at lower levels, perhaps due to its elongated hinge region and resultant increases in Fc-Fc interaction $(9,12,13)$. 
Even in the context of a paraprotein-excreting hematologic malignancy, the risk of HVS is relatively low until the serum viscosity increases above $4 \mathrm{cP}$ (9). It should be noted that, although the likelihood of HVS increases at higher levels of immunoglobulin, there is no discrete cutoff in any circumstance, and HVS should be considered for patients with characteristic symptoms and evidence of a paraprotein-secreting hematologic malignancy.

\section{SYMPTOMS AND MANAGEMENT OF HYPERVISCOSITY SYNDROME}

The predominant symptoms of HVS are mucocutaneous bleeding, ophthalmologic, and neurologic (Table 1). Hemorrhage typically occurs in small venules associated with increased viscosity in areas with minimal supporting tissue, such as the nose and oral cavity. Epistaxis is a common presenting symptom, and if present in a patient with a possible paraproteinemia, should prompt additional evaluation for HVS, particularly fundoscopic examination, as evidence of ocular HVS can be present without visual symptoms and is a treatment indication. Ophthalmologic symptoms include blurred or double vision, retinal hemorrhage. Due to the high prevalence of ophthalmologic manifestations of HVS, a fundoscopic examination should be performed in any patient with suspected HVS or with a serum $\operatorname{IgM}>3 \mathrm{~g} / \mathrm{dL}$. Characteristic retinal vein dilation with tortuous "sausage link" appearance on retinal veins can be seen. Other ophthalmic findings may include flame hemorrhages, papilledema, exudates, and microaneurysms. The most severe ophthalmologic manifestation of HVS is central retinal vein occlusion, which can result in irreversible vision loss and has been reported for patients with $\operatorname{IgM}$ and non-IgM

TABLE 1 | Clinical manifestations of hyperviscosity syndrome.

Central Nervous System

Ophthalmologic

Mucocutaneous

Cardiovascular

Other
Headache

Dizziness and vertigo

Impaired consciousness

Somnolence

Tinnitus and impaired

hearing

Ataxia

Seizure

Blurred or loss of vision Diplopia

Retinal vein occlusion

Papilledema

Retinal hemorrhage

Epistaxis

Gingival bleeding

Mucocutaneous bleeding

Gastrointestinal bleeding

High-output cardiac failure

Renal impairment

Priapism

Fatigue

Malaise

Shortness of breath paraproteinemias (14). Neurologic manifestations can range from relatively mild headache and lightheadedness to seizures and coma (4, 9, 15-20).

Plasmapheresis has been used effectively for management of HVS associated with WM since the 1950's. Despite the lack of randomized trials, this procedure rapidly reverses the clinical symptoms of hyperviscosity. Therapeutic plasma exchange (TPE) removes large-molecular-weight substances from patient plasma, including paraproteins, with the return of all cellular components to the patient. This is done by passing venous blood through an extracorporeal blood centrifugal separation device, which allows for shunting of plasma for removal. The remaining blood components are returned to the patient along with a short-acting anticoagulant, such as citrate. TPE is usually carried out using an automated blood cell separator to ensure fluid balance and maintain a normal plasma volume. Central line placement is used to allow adequate blood flow. Typically, $30-40 \mathrm{~mL} / \mathrm{kg}$ of plasma (1-1.5 plasma volumes) are removed at each procedure and replaced with isotonic 4.5 or $5.0 \%$ human albumin solution. Some services substitute $25-50 \%$ of replacement volume with $0.9 \%$ saline (21). A single plasma exchange reduces viscosity $20-30 \%$ (22). Approximately $75 \%$ of $\operatorname{IgM}$ is intravascular and therefore only one or two sessions of TPE are necessary to reduce HVS in WM (23). However, in cases of IgG-associated disease, $45-65 \%$ of IgG is intravascular. The turnover rate from extravascular to intravascular IgG is only $1-3 \%$ per hour, thus, consecutive TPE every $24-48 \mathrm{~h}$ for $4-5$ days may be necessary to reduce hyperviscosity in IgG-associated disease (24). In the absence of concurrent chemotherapy, IgG-associated disease can experience a rebound phenomenon reaching or exceeding pre-TPE levels due to persistent paraprotein production (23). Caution should be taken to avoid excessive packed red blood cell or platelet transfusions until TPE has successfully reduced hyperviscosity (15).

In general, TPE is a safe procedure, with a severe adverse event rate of $1.0 \%$ in a European registry study of over 7,000 patients undergoing filtration-based exchange $(25,26)$. Potential complications of TPE include hypotension, allergic reaction to replacement fluid, hypofibrinogenemia, and metabolic abnormalities caused by citrate use. While repeated plasmapheresis regimens can alleviate HVS symptoms, chemotherapy should be used for long-term disease control and consequent reduction of serum paraproteins.

\section{CHEMOTHERAPY MANAGEMENT FOR HYPERVISCOSITY SYNDROME}

As discussed previously, while hyperviscosity syndrome remains overall a rare occurrence, it can occur in up to a third of WM patients in their lifetime (1-6). As such, prompt treatment of hyperviscosity and the underlying WM is paramount in preventing the morbidity and mortality associated with this condition. Plasma exchange has been demonstrated to be effective in rapid symptomatic improvement as well as reversal of retinopathy (20). Plasma exchange can be continued until symptomatic improvement in HVS with concurrent initiation 
of chemotherapy (27). Chemotherapy selection is key in maintaining response and preventing HVS recurrence. Most data supports the use of a multidrug regimen in the setting of HVS (Figure 1).

Significant progress has been made in the treatment WM and lymphoplasmacytic lymphoma (LPL), including the transition to routine use of anti-CD20 monoclonal antibodies (e.g. rituximab or ofatumumab), alkylating agents (e.g., cyclophosmide or bendamustine), nucleoside analogs (e.g., cladribine or fludarabine), proteasome inhibitors (e.g., bortezomib and carfilzomib), and bruton tyrosine kinase inhibition (i.e., ibrutinib) (28).

Current chemotherapy strategies generally center on rituximab therapy in combination with other systemic agents. Overall, there is a dearth of clinical trial data comparing the different regimens, and regimen choice often depends on clinician and patient preference as well as side effect profiles (29). Combination bendamustine/rituximab (BR) is appropriate for first-line therapy, with a phase 3 clinical trial demonstrating prolonged PFS and better tolerance compared to R-CHOP for patients with indolent malignancies including LPL (30). However, given the risk of rituximab induced IgM flare, the addition of rituximab is recommended only when the serum IgM level is $<4,000 \mathrm{mg} / \mathrm{dL}$. Bortezomib/rituximab/dexamethasone (BDR) and cyclophosphamide/rituximab/dexamethasone (DRC) are other commonly-used first line regimens. A metaanalysis of $22 \mathrm{WM}$ trials found that these combinations result in comparable response rates and side effect profiles (31). Ibrutinib/rituximab combination is also an option given the relative tolerability of this regimen and ibrutinib's ability to rapidly reduce IgM levels in a matter of weeks $(27,32)$.
There is also limited frontline data on the use of ibrutinib monotherapy, although more investigation is needed prior to recommending it for patients with a history of HVS due to WM/LPL (33).

Autologous and allogeneic hematopoietic cell transplants (alloHCT) are less commonly used to treat patients with WM/LPL but may be a viable option for disease management in select cases as a long term means of disease control and prevention of HVS. An analysis of 144 patients with WM revealed that $46 \%$ of patients achieved progression-free survival 5 years after alloHCT, with a rate of relapse of $24 \%$ (34).

While advances in disease management are expected to reduce the incidence of HVS in this patient population, HVS remains a significant complication that must be carefully monitored. The treating clinician has a variety of frontline regimens to choose from, with consideration of side effect profiles and patient performance ultimately guiding treatment in the absence of strong clinical evidence supporting a specific regimen.

\section{PARADOXICAL IGM INCREASE FOLLOWING RITUXIMAB TREATMENT}

Initial rituximab therapy is associated with an increase in serum IgM concentrations in $30-70 \%$ of patients. Peak IgM was observed at a mean of 4 weeks, ranging from 1 to 8 weeks, from the start of rituximab use $(35,36)$. TPE should be performed before rituximab-based therapy in patients with an IgM level of $\geq 4,000 \mathrm{mg} / \mathrm{dL}$ or serum viscosity $>3.5 \mathrm{cp}$ (20, 37). Thereafter, IgM should be closely monitored after rituximab initiation and repeated TPE should be considered

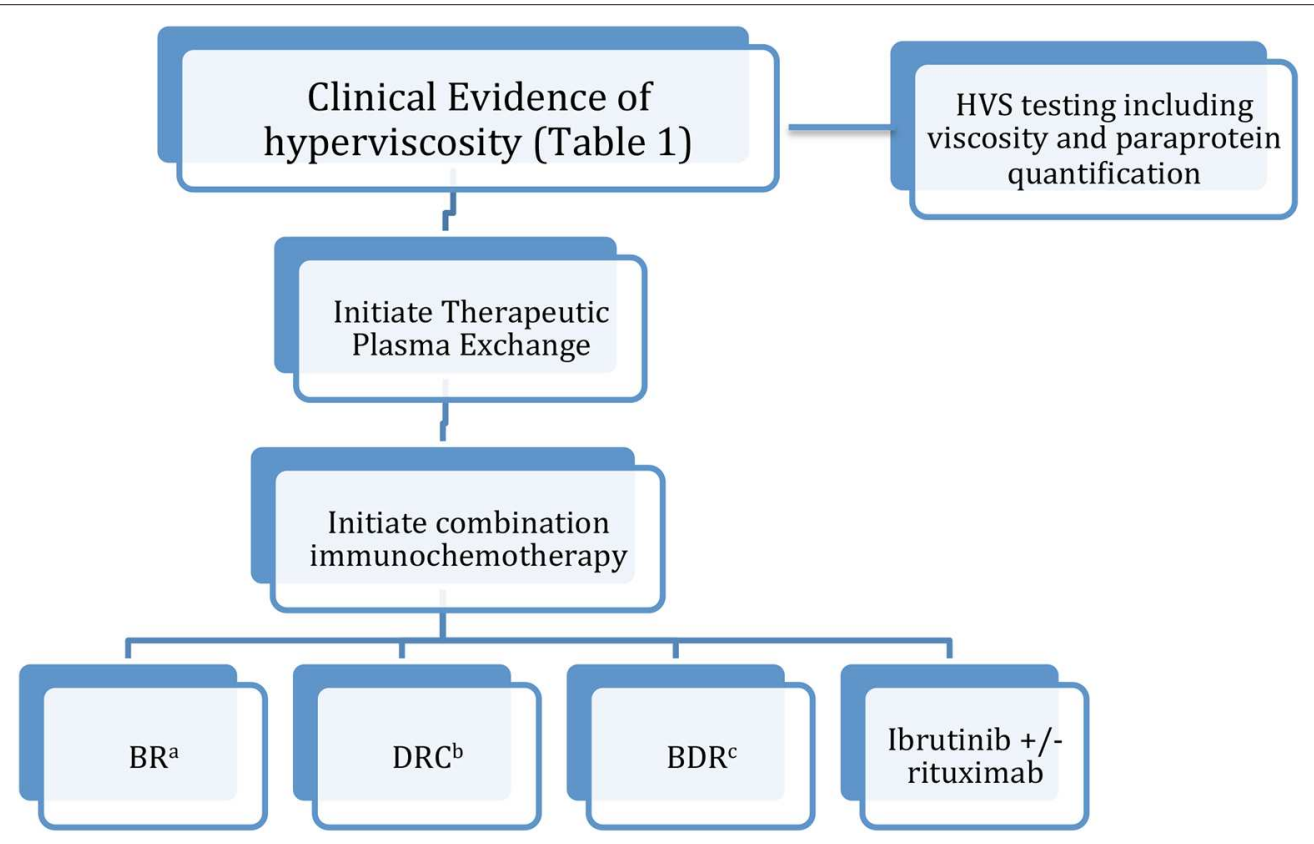

FIGURE 1 | Treatment algorithm for hyperviscosity syndrome in WM. (a) Bendamustine/rituximab. (b) Dexamethasone/cyclophosphamide/rituximab. (c) Bortezomib/dexamethasone/rituximab. 
in patients with recurrent symptomatic hyperviscosity. As rituximab-based treatment regimens become more broadly used for WM, patients should be followed closely for evidence of increased IgM production and dangerous changes in serum viscosity.

\section{SUMMARY AND CONCLUSIONS}

Hyperviscosity syndrome due to high levels of paraprotein is a serious, and potentially life-threatening, clinical complication most commonly observed in patients with WM. Plasmapheresis remains an important tool for reducing the symptoms of HVS in emergent cases and reducing serum viscosity prior to rituximab initiation. Advances in chemotherapy regimens for

\section{REFERENCES}

1. Chandy KG, Stockley RA, Leonard RC, Crockson RA, Burnett D, MacLennan IC. Relationship between serum viscosity and intravascular IgA polymer concentration in IgA myeloma. Clin Exp Immunol. (1981) 46:653-61.

2. Garcia-Sanz R, Montoto S, Torrequebrada A, de Coca AG, Petit J, Sureda A, et al. Waldenstrom macroglobulinaemia: presenting features and outcome in a series with 217 cases. Br J Haematol. (2001) 115:575-82. doi: 10.1046/j.1365-2141.2001.03144.x

3. Kyrtsonis MC, Vassilakopoulos TP, Angelopoulou MK, Siakantaris P, Kontopidou FN, Dimopoulou $\mathrm{MN}$, et al. Waldenstrom's macroglobulinemia: clinical course and prognostic factors in 60 patients. Experience from a single hematology unit. Ann Hematol. (2001) 80:722-7. doi: 10.1007/s00277-001-0385-8

4. MacKenzie MR, Babcock J. Studies of the hyperviscosity syndrome. II. Macroglobulinemia. J Lab Clin Med. (1975) 85:227-34.

5. Mehta J, Singhal S. Hyperviscosity syndrome in plasma cell dyscrasias. Semin Thromb Hemost. (2003) 29:467-71. doi: 10.1055/s-2003-44554

6. Riccardi A, Gobbi PG, Ucci G, Bertoloni D, Luoni R, Rutigliano L, et al. Changing clinical presentation of multiple myeloma. Eur J Cancer. (1991) 27:1401-5. doi: 10.1016/0277-5379(91)90020-E

7. Daniel R, Chan RY. Hyperviscosity syndrome in splenic marginal zone lymphoma. Blood. (2018) 132:1627. doi: 10.1182/blood-2018-07-863787

8. Crawford J, Cox EB, Cohen HJ. Evaluation of hyperviscosity in monoclonal gammopathies. Am J Med. (1985) 79:13-22. doi: 10.1016/0002-9343(85)90540-6

9. Kwaan HC, Bongu A. The hyperviscosity syndromes. Semin Thromb Hemost. (1999) 25:199-208. doi: 10.1055/s-2007-994921

10. Gustine JN, Meid K, Dubeau T, Hunter ZR, Xu L, Yang G, et al. Serum IgM level as predictor of symptomatic hyperviscosity in patients with Waldenstrom macroglobulinaemia. Br J Haematol. (2017) 177:717-25. doi: 10.1111/bjh.14743

11. Somer T. Rheology of paraproteinaemias and the plasma hyperviscosity syndrome. Baillieres Clin Haematol. (1987) 1:695-723. doi: 10.1016/S0950-3536(87)80021-5

12. Capra JD, Kunkel HG. Aggregation of gamma-G3 proteins: relevance to the hyperviscosity syndrome. J Clin Invest. (1970) 49:610-21. doi: 10.1172/JCI106272

13. Papadea C, Check IJ. Human immunoglobulin G and immunoglobulin G subclasses: biochemical, genetic, and clinical aspects. Crit Rev Clin Lab Sci. (1989) 27:27-58. doi: 10.3109/10408368909106589

14. Rajagopal R, Apte RS. Seeing through thick and through thin: retinal manifestations of thrombophilic and hyperviscosity syndromes. Surv Ophthalmol. (2016) 61:236-47. doi: 10.1016/j.survophthal.2015. 10.006

15. Halfdanarson TR, Hogan WJ, Madsen BE. Emergencies in hematology and oncology. Mayo Clin Proc. (2017) 92:609-41. doi: 10.1016/j.mayocp.2017.02.008
WM will reduce the incidence of acute HVS through long-term management of underlying disease.

\section{AUTHOR CONTRIBUTIONS}

RC responsible for manuscript design. The final article was critically reviewed and approved for publication by RC, SR, and AW. All authors contributed to the writing and editing process and collaborated on the manuscript.

\section{FUNDING}

SR would like to disclose funding from T32 HG008341 and the Jim and Carol O'Hare Fund.

16. MacKenzie MR, Brown E, Fudenberg HH, Goodenday L. Waldenstrom's macroglobulinemia: correlation between expanded plasma volume and increased serum viscosity. Blood. (1970) 35:394-408. doi: 10.1182/blood.V35.3.394.394

17. MacKenzie MR, Lee TK. Blood viscosity in Waldenstrom macroglobulinemia. Blood. (1977) 49:507-10. doi: 10.1182/blood.V49.4.507.507

18. Perry MC, Hoagland HC. The hyperviscosity syndrome. JAMA. (1976) 236:392-3. doi: 10.1001/jama.1976.03270040048034

19. Stone MJ. Waldenstrom's macroglobulinemia: hyperviscosity syndrome and cryoglobulinemia. Clin Lymphoma Myeloma. (2009) 9:97-9. doi: 10.3816/CLM.2009.n.026

20. Stone MJ, Bogen SA. Evidence-based focused review of management of hyperviscosity syndrome. Blood. (2012) 119:22058. doi: 10.1182/blood-2011-04-347690

21. Bachowski G, Brunker PAR, Eder PAR, Fialkow LB, Fridey JL, Goldberg C, et al. Blood component modification. In: Fridey J, Marcus L, editors. A Compendium of Transfusion Practice Guidelines. American Red Cross (2017).

22. Ballestri M, Ferrari F, Magistroni R, Mariano M, Ceccherelli GB, Milanti $\mathrm{G}$, et al. Plasma exchange in acute and chronic hyperviscosity syndrome: a rheological approach and guidelines study. Ann Ist Super Sanita. (2007) 43:171-5.

23. Kaplan A. A Pracitical Guide to Therapeutic Plasma Exchange. Malden, MA: Blackwell Science (1999).

24. Padmanabhan A, Connelly-Smith L, Aqui N, Balogun RA, Klingel R, Meyer A, et al. Guidelines on the use of therapeutic apheresis in clinical practice - evidence-based approach from the writing committee of the American Society for Apheresis: the eighth special issue. J Clin Apher. (2019) 34:171-354. doi: 10.1002/jca.21705

25. Mörtzell Henriksson M, Newman E, Witt V, Derfler K, Leitner G, Eloot S, et al. Adverse events in apheresis: an update of the WAA registry data. Transfus Apher Sci. (2016) 54:2-15. doi: 10.1016/j.transci.2016. 01.003

26. Lemaire A, Parquet N, Galicier L, Boutboul D, Bertinchamp R, Malpettes $\mathrm{M}$, et al. Plasma exchange in the intensive care unit: technical aspects and complications. J Clin Apher. (2017) 32:405-12. doi: 10.1002/jca. 21529

27. Kastritis E, Leblond V, Dimopoulos MA, Kimby E, Staber P, Kersten MJ, et al. Waldenstrom's macroglobulinaemia: ESMO clinical practice guidelines for diagnosis, treatment and follow-up. Ann Oncol. (2019) 30:8602. doi: 10.1093/annonc/mdy466

28. Cornell RF, Burns LJ, Bachanova V. Why Waldenstom macroglobulinemia is not just another indolent lymphoma. Int J Hematol Oncol. (2014) 3:95-8. doi: 10.2217/ijh.14.5

29. Treon SP. How I treat Waldenström macroglobulinemia. Blood. (2015) 126:721-32. doi: 10.1182/blood-2015-01-553974

30. Rummel MJ, Niederle N, Maschmeyer G, Banat GA, von Grunhagen U, Losem $\mathrm{G}$, et al. Bendamustine plus rituximab versus $\mathrm{CHOP}$ plus rituximab as first-line treatment for patients with indolent and mantle-cell lymphomas: 
an open-label, multicentre, randomised, phase 3 non-inferiority trial. Lancet. (2013) 381:1203-10. doi: 10.1016/S0140-6736(12)61763-2

31. Zheng YH, Xu L, Cao C, Feng J, Tang H-L, Shu M-M, et al. Rituximab-based combination therapy in patients with Waldenström macroglobulinemia: a systematic review and meta-analysis. Onco Targets Ther. (2019) 12:275166. doi: 10.2147/OTT.S191179

32. Dimopoulos MA, Tedeschi A, Trotman J, Garcia-Sanz R, Macdonald $\mathrm{D}$, Leblond $\mathrm{V}$, et al. Phase 3 Trial of Ibrutinib plus Rituximab in Waldenstrom's Macroglobulinemia. N Engl J Med. (2018) 378:2399410. doi: 10.1056/NEJMoa1802917

33. Treon SP, Gustine J, Meid K, Yang G, Xu L, Liu X, et.al. Ibrutinib monotherapy in symptomatic, treatment-naïve patients with waldenström macroglobulinemia. J Clin Oncol. (2018) 36:2755-61. doi: 10.1200/JCO.2018.78.6426

34. Cornell RF, Bachanova V, D'Souza A, Woo-Ahn K, Martens M, Huang J, et al. Allogeneic transplantation for relapsed waldenstrom macroglobulinemia and lymphoplasmacytic lymphoma. Biol Blood Marrow Transplant. (2017) 23:60-6. doi: 10.1016/j.bbmt.2016.10.010

35. Dimopoulos MA, Zervas C, Zomas A, Kiamouris C, Viniou NA, Grigoraki V, et al. Treatment of Waldenstrom's macroglobulinemia with rituximab. J Clin Oncol. (2002) 20:2327-33. doi: 10.1200/JCO.2002.09.039
36. Treon SP, Branagan AR, Hunter Z, Santos D, Tournhilac O, Anderson KC. Paradoxical increases in serum IgM and viscosity levels following rituximab in Waldenstrom's macroglobulinemia. Ann Oncol. (2004) 15:14813. doi: $10.1093 /$ annonc/mdh403

37. Ansell SM, Kyle RA, Reeder CB, Fonseca R, Mikhael JR, Morice WG, et al. Diagnosis and management of Waldenstrom macroglobulinemia: mayo stratification of macroglobulinemia and risk-adapted therapy (mSMART) guidelines. Mayo Clin Proc. (2010) 85:824-33. doi: 10.4065/mcp. 2010.0304

Conflict of Interest: The authors declare that the research was conducted in the absence of any commercial or financial relationships that could be construed as a potential conflict of interest.

Copyright (๑) 2020 Weaver, Rubinstein and Cornell. This is an open-access article distributed under the terms of the Creative Commons Attribution License (CC BY). The use, distribution or reproduction in other forums is permitted, provided the original author(s) and the copyright owner(s) are credited and that the original publication in this journal is cited, in accordance with accepted academic practice. No use, distribution or reproduction is permitted which does not comply with these terms. 